\title{
Cross-Cultural Examination on Content Bias and Helpfulness of Online Reviews: Sentiment Balance at the Aspect Level for a Subjective Good
}

\author{
Makoto Nakayama \\ DePaul University \\ mnakayama@cdm.depaul.edu
}

\author{
Yun Wan \\ University of Houston-Victoria \\ wany@uhv.edu
}

\begin{abstract}
Online reviews can be fraught with biases, especially on experience goods. Using multilingual sentiment analysis software, we examined the characteristics of review biases and helpfulness at the aspect level across two different cultures. First, we found the lopsidedness of emotions expressed over the four key aspects of Japanese restaurant reviews between Japanese and Western consumers. Second, helpful reviews have sentiments expressed more evenly over those aspects than average for both Japanese and Western consumers. Third, however, there are significant differences over how sentiments are spread over aspects between them. Westerners found reviews helpful when reviews focused less on food and more on service. In addition, Japanese customers were more concerned with savings whereas Westerners paid attention to whether they are getting their money's worth. These findings point to future research opportunities for leveraging sentiment analysis over key aspects of goods, particularly those of experience/subjective goods, across different cultures and customer profile categories.
\end{abstract}

\section{Introduction}

While valuable, online reviews can be fraught with content biases and credibility issues [8, 22]. A well-recognized content bias is the bimodal tendency of favorable and unfavorable opinions [8, 23]. Credibility and helpfulness are especially critical when it comes to reviews on hospitality businesses [62] since consumers' subjective feelings and experiences play major roles. To counter the variance of review quality, many review sites use votes on "usefulness" or "helpfulness" in judging the value of restaurant dining experience. This paper defines helpfulness of a review as the extent to which it helps consumers to shop by providing pertinent information [45, 54]. In this context, "usefulness" and "helpfulness" are interchangeable [54].

Helpfulness votes are considered de facto indicators of review quality [47]. Previous studies [1, $6,24,35,45,54,61]$ indicate review helpfulness is influenced by three categories of factors [47]: review characteristics (e.g., length, readability, semantics, negative words, innovativeness), review meta information (e.g., valence, total vote counts, review age, reviewer credibility), and other factors associated with reviews (e.g., good type, price, sales rank, rating inconsistency). Those factors are not necessarily linear. For example, lengthier reviews correlated with higher helpfulness but have a threshold [38]. Some factors are quadratic, such as review age [54] and valence (star rating) [35, 45], depending on the specifics of a statistical model. Due to the model complexity, the insights from those models remain largely abstract and do not directly relate to the characteristics or attributes of the product. Those extant studies were conducted in a monocultural environment. Few previous studies have addressed cross-cultural differences of helpful reviews at the product aspect level.

In recent decades, Asian ethnic foods and restaurants have seen a remarkable growth in popularity in the United States [28]. In particular, Japanese food, as a type of "healthy food," has become popular worldwide as a result of a health conscious trend [29]. As Asian ethnic foods become increasingly popular, competition among Asian food restaurants intensified, and authenticity of food alone would not secure a competitive edge since customers have become more familiar with ethnic food and the choices available to them [27]. The new challenge for ethnic restaurants is deciding how authentic they should be, knowing that the preferences of local and tourist customers are probably different [26]. Can managers of ethnic restaurants ascertain those different expectations from online reviews, especially when the availability of translation tools enables both local and tourist customers to evaluate ethnic restaurants from a variety of viewpoints? 
The main research question of this study is How differently do Japanese and Western consumers express their emotions over the key aspects of Japanese restaurant dining experience in helpful reviews? Adopting the descriptions of "aspect" [39] and "facet" [72] in text analysis, we define aspect as a feature or attribute that leads to valuable insights concerning restaurant dining experience. Based on this definition, our study compares the distribution of emotional sentiments over key aspects in reviews between Japanese and Western consumers to know the characteristics of helpful reviews across two different cultures. ${ }^{1}$

This paper first provides the research background and hypotheses. It then presents our method, results, and implications. It ends with limitations, future study agenda, and the conclusion.

\section{Background and Hypotheses}

Restaurant reviews. A content analysis of reviews on full-service restaurants in London demonstrated that the frequencies of topics mentioned are ranked in the order of food (96-98\%), service (73-92\%), atmosphere/ambience (51-53\%), price $(27-29 \%)$, menu $(27 \%)$, and restaurant interior design/décor (8-10\%) [55]. The same study also notes that the profiles of reviews were relatively stable over periods and predominantly positive. An analysis of reviews poses a few challenges. First, restaurant dining is considered a subjective experience, and thus it is considered a type of good known as an experience good [52] or hedonic good [11]. That is, there are few directly measurable, objective dimensions for dining experience in contrast to gas mileage for automobiles and printing speed for printers. Second, review content is generally short in length and may be specific to the type of restaurant [64]. Recent studies include those focusing on competitive market analysis [18], reviewer sentiments on review star rating [16], review characteristics on review helpfulness [31, 53], and subtopic impact on restaurant ratings [30].

Aspects of restaurant reviews. Previous studies have attempted to classify aspects in restaurant reviews. An aspect is generally defined as a distinct component or attribute of text content [2, 39]. These studies used various content and text analytic methodologies. Many focused on associations between the frequencies of terms and

\footnotetext{
${ }^{1}$ In this paper, Western customers refer to English-speaking customers in the United States, United Kingdom, Canada and Germany.
}

positive/negative sentiments (opinions), using such techniques as Latent Semantic Analysis and Latent Dirichlet Allocation [32, 64]. Some text analyses [4, 17] apply supervised modeling with manual intervention and other unsupervised modeling without any human involvement to categorize terms $[64,71]$. On the other hand, aspects are also defined experientially. Popular restaurant review websites and publications (e.g., Yelp, TripAdvisor, Zagat, AAA Diamond Rating) define aspects, and some studies $[15,16]$ use them to create word lists under those aspects. Other studies $[17,55]$ referenced them when applying computational analyses and/or manual content evaluations. While aspects of dining experience are not standardized, commonalities among those previous studies $[4,15,16,17,18,55$, $64,65,66,71]$ are food, service, physical environment (e.g., ambience, décor, location), and price fairness.

Well-rounded, minimally biased reviews. Bias is defined as "any process at any stage of inference which tends to produce results or conclusions that differ systematically from the truth" [60]. Of 17 known biases in online reviews, there are four related to the review writer and eight associated with the review reader [46]. However, because restaurant reviews are largely subjective, it is not certain how we recognize "biased" reviews objectively based on the "truth." In this study, we propose to assess review content bias as the lopsidedness of subjective sentiments placed in key review aspects. This approach is based on emotional bias defined as "the tendency to process selectively emotional (usually negative) information relative to positive and neutral stimuli" [5]. The root of this definition is further traced back to attention bias or "the propensity to look for, and be attentive to certain information in the environment" [67]. Thus, biases are equivalent to lopsided selectivity in multiple criteria evaluation. In decision-making domains, we can find theoretical foundations in multiple criteria decision-making and multi-attribute utility theory [12]. While intuitively obvious, previous review studies have not addressed the lopsided attention to key attributes or aspects. Before focusing on cross-cultural differences, we posit that helpful reviews are characterized by the even spread of attentions. Since restaurant dining is an experience (subjective) good, sentiment spread over aspects approximates the balance of attention to meaningful attributes. Thus, we hypothesize the following: 
H1: Review content bias (lopsided sentiment variance over aspect) is lower in helpful reviews than in all reviews for both Japanese and Western cultures.

Cross-cultural differences in restaurant reviews. Among the four dimensions (food, service, physical environment, price fairness), the next logical question is how equally sentiments spread over those aspects. Previous research shows that Westerners are more concerned about service quality than Easterners. While Japanese care more about value than American customers, the latter value friendliness, being personal, authenticity, and promptness more than Japanese customers [68, 69, 70]. In addition, Japanese customers give lower ratings to superior service while being more forgiving of poor service than Americans [36]. According to Hofstede [20, 21, 44], six dimensions differentiate national cultures. These dimensions can be quantified as indexes: (1) power distance index, (2) individual vs. collectivism, (3) uncertainty avoidance index, (4) masculinity vs. femininity, (5) long-term orientation vs. short-term orientation, and (6) indulgence vs. restraint. Compared with the three English-speaking countries (US, UK, and Canada), Japanese culture scores higher in masculinity, uncertainty avoidance, and long-term orientation but lower in individualism and indulgence. Perceptions of service quality vary across different cultures on Hofstede's dimensions [14]. Upon receiving poor service, customers from cultures with lower individualism or greater uncertainty avoidance, such as the Japanese, tend to be more likely to praise superior service but not to switch service providers, spread negative word of mouth, or complain [40]. At the same time, the interest in food may be equally important in both cultures. Food quality is the most important category of experience, strongly related to the motivations of post-dining customer behaviors, such as sharing with friends or posting online reviews $[42,49]$. Thus, if we focus on sentiment shares, the relative focal interest of Westerners shifts to service from food more so than Japanese in helpful reviews. Therefore, we posit the following:

H2: The aspect sentiment shares of Westerners shift more for service and less for food than those of Japanese in helpful reviews.

Past studies [41, 42] suggest that environmental hygiene/cleanliness of Asian ethnic restaurants is quite important for Westerners. They look for a positive physical environment when dining at Asian ethnic restaurants. Japanese culture and business organizations are noted to value cleanliness [7, 25].
However, the focus of cleanliness in restaurants may be different for Japanese. Rooted in shame culture [3], Japanese are likely to emphasize self-image in the eyes of others. Such a tendency may also apply to their evaluation of restaurant image or environment, as they may deem any inferior environmental attributes as their own shame. This suggests that the Japanese may focus more on the negative physical environment aspect than Westerners, leading to our next hypothesis:

H3a: In helpful reviews, Westerners focus more on the positive physical environment aspect than the Japanese, whereas the latter focus more on the negative physical environment aspect than Westerners.

A study [19] of mobile commerce service shows that customers in Hong Kong appreciate more discounts, free trials, and lower costs than customers in the United Kingdom. The high long-term orientation index Hofstede [20, 21, 44] identified in Japanese culture suggests that Japanese consumers are thriftier and more price sensitive than Westerners. However, Westerners are sensitive to price for its worth. As an example, a study by Choi and Mattila [10] reports that US customers of hotels perceive variable pricing practices as fairer than Korean customers. Mattila and Patterson [43] frame such differences as distributive vs. interactional justice. In the context of service delivery, Westerners are more interested in receiving compensation proportional to any loss or inconvenience they have. In contrast, Easterners tend to focus more on the manner of customer treatment than on receiving compensation. For price fairness, Westerners are more interested in getting (neutral) or not getting (negative) their money's worth than the Japanese, whereas the latter are more interested in savings (positive) or no savings (neutral). Thus, we hypothesize:

H3b: In helpful reviews, Westerners focus more on the negative price fairness (e.g., not getting their money's worth) aspect than the Japanese, whereas the latter focus more on the positive price fairness (e.g., savings) aspect than Westerners. 


\section{Method}

Data sources. We chose Yelp (yelp.com) as the source of reviews in the two cultures. Yelp is not only one of the most popular review sites [57], but also hosts Japanese reviews on an identical website (yelp.co.jp) using the same review format and functionality. This allows direct comparison of reviews in English and Japanese. The English reviews were obtained through the Yelp Dataset Challenge in 2016. We acquired the Japanese reviews directly from Yelp in the beginning of 2016. Of those reviews, we selected those that Yelp classifies with the "Japanese restaurant" business category. This study used 56,159 reviews from Yelp's Japanese site in the Japanese language and 76,704 from Yelp in the English language.

The restaurants in Japan were in Tokyo and Osaka, whereas the locations of Western counterparts were in the United States (80.4\%), Canada (16.2\%), the United Kingdom (2.9\%), and Germany $(0.5 \%)$. We only used reviews written in English for Canada and Germany. Of the US reviews, $77.9 \%$ were from the Arizona and Nevada areas.

Japan is a mono-ethnic country with a small proportion of Western foreign residents. ${ }^{2}$ In the United States, the percentage of foreign-born population is high, particularly on the Eastern and Western Coast. ${ }^{3}$ On the other hand, the demographics in non-US cities we studied (Quebec in Canada, Edinburgh in the United Kingdom, and Karlsruhe in Germany) consist of predominantly domestic and/or Western populations. Considering such realities, we used those English reviews inclusively to minimize the biases associated with the cultural diversity within the United States.

While the datasets do not contain specific price range information, the spread of restaurant locations (Figure 1) indicates that the samples contain a reasonably broad spectrum of Japanese restaurants for our analysis.

2

https://en.wikipedia.org/wiki/Demography of Japan\#Foreign resi $\underline{\text { dents }}$

3

https://en.wikipedia.org/wiki/List_of_United_States_cities by for eign-born_population

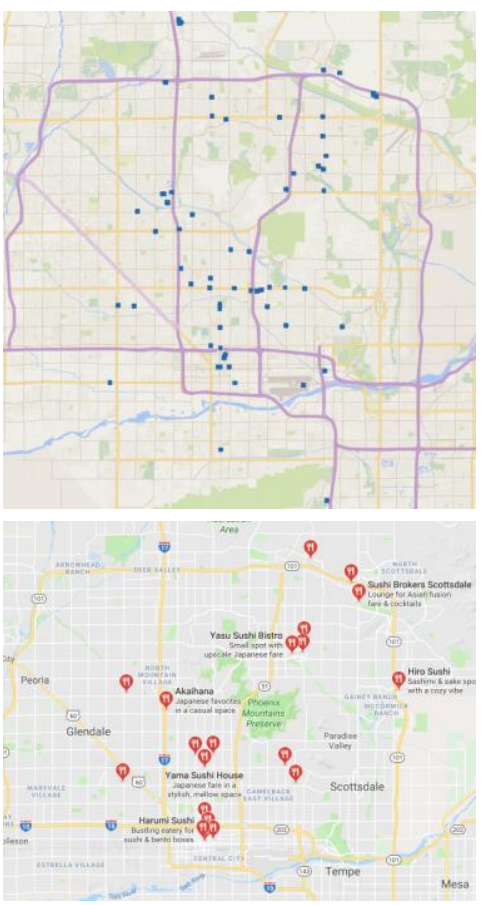

Figure 1. The geographic spread of 74 restaurant locations in Phoenix, Arizona (above) vs. the first 20 results of a Google search map

Analytical focus and tools. Japanese restaurants are often part of "hybrid" Asian dining businesses in Western countries. Given this cultural integration, it is not always possible to isolate pure "Japanese restaurants." We thus chose to focus on the 10 most popular entrée items (Table 1) within the Yelp reviews in Japanese and English.

Table 1. Review Count by Entrée Item

\begin{tabular}{lll}
\hline Entrée Item & Japan & West \\
\hline bento & 435 & 1,846 \\
curry rice & 3,701 & 633 \\
fried rice & 706 & 3,936 \\
gyoza & 1,265 & 1,837 \\
miso soup & 1,007 & 3,317 \\
ramen & 4,449 & 8,425 \\
soba & 3,368 & 486 \\
sushi & 3,667 & 43,555 \\
tempura & 1,007 & 5,473 \\
udon & 1,431 & 1,550 \\
\hline
\end{tabular}

The Japanese language uses three scripts: kanji (of Chinese origin), hiragana, and katakana [37]. Such orthographic differences make direct textual comparisons (e.g., character and review lengths) impossible between Japanese and English reviews, as with comparisons between Chinese and English 
reviews [9]. For this reason, we used multilingual text analytical software, IBM Watson Explorer Content Analytics 11.0.1 (hereafter, WCA). WCA uses the same analytical technology, TAKMI (Text Analysis and Knowledge Mining) [50], with a precise sentiment detector [33] for both languages. The software is used to investigate vehicle defects by the US National Highway Traffic Safety Administration [51].

Analytical metric. Typically, frequency (the number of time a particular keyword is used in a document set) has been used for sentiment analysis. However, the same frequency does not signify the identical sentiment level when review counts vary between two samples (e.g., the counts of reviews containing the entrée items "ramen" and "bento" are 4,449 and 435 among the Japanese reviews). For this reason, this study used correlation [73] as the main metric of analysis. Correlation is defined as the ratio of (a) the review proportion containing a particular entrée item given a sentiment expression over (b) the review proportion of containing a particular entrée item given all the reviews [48]. Suppose that $30 \%$ of all reviews mention "ramen." The phrase "service is excellent" is seen together with the term "ramen" in some reviews, and the question is how often those two, "ramen" and "service is excellent," appear together. Of all the uses of "service is excellent," $30 \%$ appear in those reviews referring to "ramen" in Country $\mathrm{X}$ and $15 \%$ in Country $\mathrm{Y}$. In that case, the correlations between "ramen" and "service is excellent" are $1(=30 \% / 30 \%)$ for Country $\mathrm{X}$ and 0.5 $(=15 \% / 30 \%)$ for Country Y. This metric is suitable for this study because it is not affected by corpus sizes.

Analytical procedure. We took a multi-pronged approach. After selecting reviews that contain one of the 10 entrée items, we used WCA first to extract the top 50 sentiment phrases associated with each entrée item based on their correlation values, given the increase of cumulative correlation shares becomes negligible beyond those 50 phrases. Once we extracted 50 positive and 50 negative sentiment phrases, five qualified evaluators at a university in the U.S. Midwest independently categorized phrases into one of the four review aspects (food, service, physical environment, and price fairness) or "other" (uncategorizable). When they disagreed, the evaluation coordinator ran several rounds of discussion among the evaluators. If disagreements remained, majority rule prevailed. For the "other" sentiment phrases, we further queried the highly correlated sentiment nouns (e.g., "it was great") to see if they were predicating categorizable nouns (e.g., "sauce"). Finally, using categorized terms, we used WCA to tabulate the correlation values (a) by sentiment orientation as well as (b) by all the reviews or helpful reviews (those voted as "useful" more than once) for each entrée item.

\section{Results}

Figure 2 shows the average positive sentiments of the 10 entrée items over review aspects for Japanese and Western reviews. For example, the average correlations between positive sentiment terms and entrée items exceed 25 for food and NA (other) among all reviews in the Japanese sample. Those correlations in the helpful reviews, however, are less than half of all reviews. For both Japanese and Western consumers, the correlation lines are visibly flatter in the helpful reviews than in all reviews.

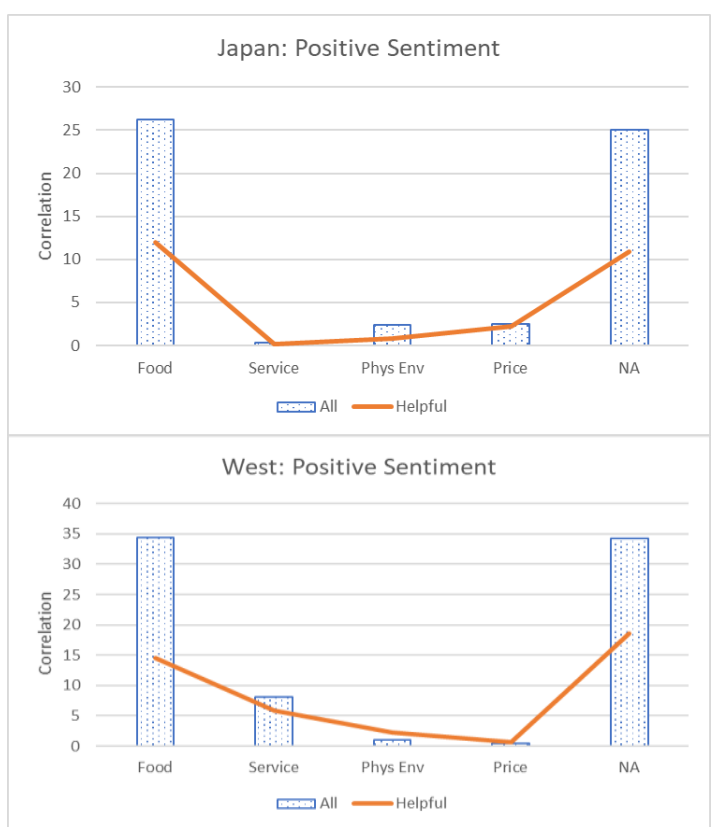

Figure 2. Average Positive Sentiment (All vs. Helpful Reviews)

Figure 3 shows similar changes from all reviews to the helpful reviews for the negative sentiments. The distributions of the average correlations between the 10 entrée items and negative sentiment terms flatten from all reviews to the helpful reviews for both Japanese and Western reviews. Again, large changes are seen in food and NA (other). While all reviews see high correlations between the entrée items and the (unclassifiable) other negative sentiment terms, the helpful reviews have much lower correlations than all reviews. The correlations 
between food and negative sentiment terms also show the same distribution changes. That is, the negative sentiments in the helpful reviews are seen in more specific aspects than in the unclassifiable aspect. It is noteworthy that the correlations for food and service are equal (4.89) among the reviews by the Westerners.

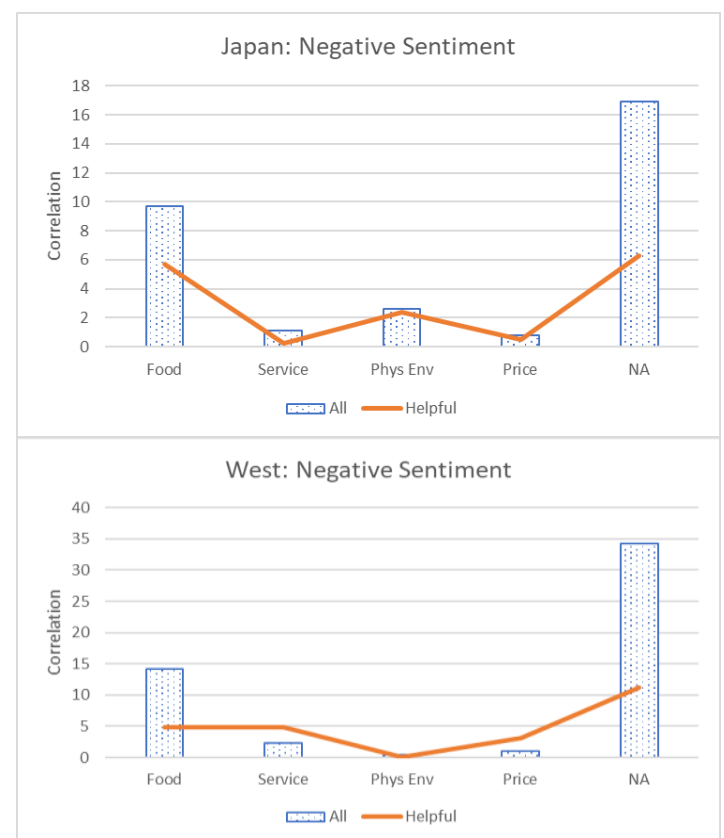

Figure 3. Average Negative Sentiment (All vs. Helpful Reviews)

To confirm further, the average variances of the 10 entrée items were estimated, and their differentials from all to helpful reviews are shown in Table 2. For both positive and negative sentiments, the variances are significantly lower in helpful reviews than those in all reviews. Thus, $\mathbf{H 1}$ (the aspect distributions are more even for both cultures in helpful reviews than all reviews) is supported.

Table 2. Sentiment Variance Change from All to Helpful Reviews

\begin{tabular}{lll}
\hline Variance Change & Positive & Negative \\
\hline Japan & -135.3 & -44.4 \\
West & -197.1 & -141.7 \\
\hline
\end{tabular}

$\mathrm{H} 2$ and $\mathrm{H} 3$ concern how the correlations between sentiments and entrée items re-distribute themselves across individual review aspects (food, service, physical environment, price fairness) within each culture and how those re-distributions compare between the two cultures. Given the inherent differences in languages and cultures in the Western and Japanese samples, we cannot directly compare the absolute correlation levels across the two. We first calculated the correlation shares between the aspects (including NA or unclassifiable) within each culture and then compared the magnitudes of redistributions between the two cultures. Figure 4 shows the results of such comparisons.

For example, the positive sentiment differential on food is $-8.8 \%$ in Figure 4 . This value was determined in two steps. First, we calculated the Japanese culture having a "food" share reduction of $0.5 \%$ and the Western culture seeing a larger share reduction of $9.4 \%$. Thus, the "food" differential was $(-9.4 \%)$ - ($0.5 \%)=-8.8 \%$ between the two cultures. In both cultures, the emphasis on the "food" aspect is less, but the extent of de-emphasis is greater in the Western culture than the Japanese culture.

Similarly, in the negative sentiment differentials, the Western culture has the "service" share increase of $15.9 \%$ while the Japanese culture has the reduction of $2.3 \%$. The total differential is $15.9 \%-(-2.3 \%)=$ $18.2 \%$. In other words, the Western culture has increased emphasis on service more than the Japanese culture.
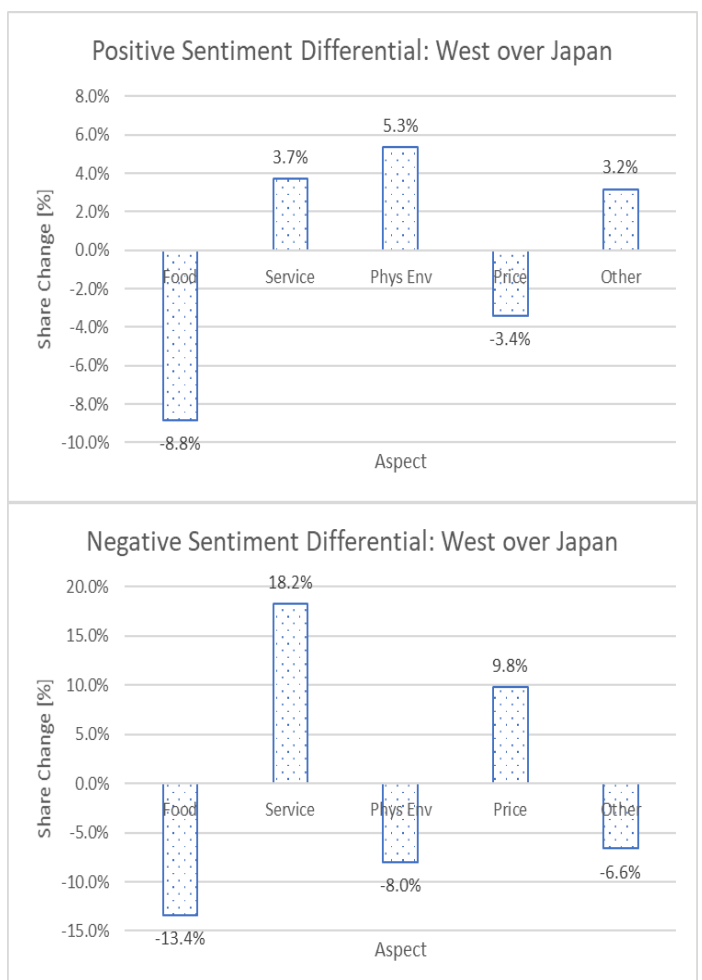

Figure 4. Sentiment Share Differentials of Westerners over Japanese

In Figure 4, both positive and negative sentiments have the Western culture de-emphasizing "food" more than the Japanese culture. On the other hand, 
the reserve is seen on "service"; the Western culture's sentiment changes on "service" are greater than those of the Japanese culture. Thus, $\mathbf{H 2}$ (the aspect sentiment shares of Westerners shift more for service and less for food than those of Japanese in helpful reviews) is supported.

Figure 4 also shows that the emphasis and deemphasis by Westerners and Japanese people on physical environment and price fairness are crossways. The Japanese shift more attention to poor physical environment and great price, whereas Westerners place more emphasis on the positive aspects of physical environment and on the negative aspects of price fairness. This affirms both H3a (in helpful reviews, Westerners focus more on the positive physical environment aspect than the Japanese, whereas the latter focus more on the negative physical environment aspect than Westerners) and H3b (in helpful reviews, Westerners focus more on the negative price fairness aspect than the Japanese, whereas the latter focus more on the positive price fairness aspect than Westerners).

\section{Implications}

Assessing the characteristics of helpful (i.e., useful) reviews at the aspect-level offers qualitative insights into what prospective customers would look for in products or services. Previous studies [8, 23] noted the J-curved distribution of opinions. Beyond that, current review helpfulness analysis using review characteristics, review meta information, and other factors remains largely abstract because models tend to involve many variables including quadratic ones. Their outcomes are harder to interpret for assessing business implications than those of our approach.

The result of $\mathrm{H} 1$ implies helpful reviews are those in which reviewers did not express their emotions in a lopsided manner on particular aspects of restaurant dining experience. A reviewer may like (positive sentiment) or dislike (negative sentiment) certain aspects of dining. Regardless, review readers find reviews helpful when the reviewer's attentions are paid equally to food, service, physical environment, price fairness, and anything else. Given restaurant reviews are often short [64], how sentiment is expressed equally over major aspects can serve as an important benchmark of review helpfulness.

The findings of $\mathrm{H} 2$ and $\mathrm{H} 3$ extend the above implication from the cross-cultural perspective. Sentiment distributions not only change from all reviews to helpful reviews, but also the specifics of their changes vary between the two different cultures. As hypothesized, Westerners prefer to learn more about how reviewers felt about service quality and less about food quality than the Japanese do. Moreover, Westerners focus more on negative service quality than positive service quality. On the other hand, Japanese readers find helpful those reviews that contain more positive emotions over price fairness than otherwise. This aligns well with the high long-term orientation of the Japanese, in accordance with Hofstede's cross-cultural dimensional theory $[20,21,44]$.

Managerial implication. Despite today's globalization, individual culture still matters. Ethnic restaurant managers should optimize the mix of customer service delivery for customers' predominant cultural preferences. Figures 2 and 3 show the criticality of food quality compared with other aspects. However, previous studies show that food quality is not the only key driver for customer satisfaction and loyalty. Other critical factors include responsiveness of frontline employees and price [59], as well as restaurant image and perceived value [58]. One study [34] even notes that a customer's predining expectations and briefs play a significant role. Thus, everything can count in today's hypercompetitive restaurant business. For example, Japanese restaurant managers in Tokyo highlight their service when attracting Western tourists, but emphasize fine details of food quality when attracting domestic customers. Concerning price fairness, Japanese customers focus on positives (savings) whereas Westerners pay attention to negatives (not getting their money's worth). Such parity should be reflected in advertisements and market communications.

Theoretical implication. The results of the study extend findings from previous studies $[1,6,24,35$, $45,54,61]$ on the impact factors for review helpfulness by connecting helpfulness to the balance and cultural influence of emotional expressions. The result of $\mathrm{H} 1$ calls for empirical investigations into how attentions are equitably spread over key review aspects. The findings of such investigations might relate to the fairness framework [63] in service recovery and fairness theory [13] or distributive justice [56] in legal domains. For cross-cultural analysis, the study finds it helpful to apply relatively unused concepts like shame and guilt, explored in Ruth Benedict's study The Chrysanthemum and the Sword (1967), while Hofstede's cross-cultural dimensional theory remains valid.

For online review research, this study shows the importance of aspect-based review analysis. In the computer-scientific approach to review text analyses, aspects are not purely identified by computational 
algorithms, but rather are often abstracted and named by the researchers based on groups of representative aspect seeds (candidates) identified by certain algorithms. As an example, Zhu et al. (2009) used an aspect "service" based on such aspect seeds as 'waiter,' 'considerate,' 'service,' 'good service,' and 'friendly.' It is imperative to ground the choice of aspects with theory and practice of a given business domain.

\section{Limitations and Future Research Agenda}

The results were obtained in the context of Japanese ethnic restaurants, and so future studies should aim to broaden the scope, examining, for example, reviews on Chinese/German restaurants between Chinese/German and Japanese customers by using the same multilingual software, WCA. They should also assess how results might vary for other ethnic restaurants between their home culture and an external culture. The validity of aspect-level analysis should be further examined beyond restaurant reviews. Future studies should focus on, for instance, products and services whose key aspects can be ascertained from publications like Consumer Reports. Finally, while the study is one of the first crosscultural review content analyses, it relied on the qualitative comparisons of sentiment distributions across two cultures. Follow-up studies should explore quantitative approaches, possibly using multiple models.

\section{Conclusion}

This study fills the research gaps of extant studies in two ways. First, it demonstrates how review helpfulness (or bias) is represented by the balance of sentiments expressed over key aspects of review contents. Second, using multilingual sentiment analysis software, it shows that specifics of review sentiment balance vary between two different cultures concerning dining experience at ethnic restaurants.

The results of this study show promising directions for assessing review content biases and helpfulness on experience goods and services. Due to the subjective nature of those goods, knowing what characterizes helpful reviews has not been clear at the product attribute level.

The results of this study revealed the commonality and differences in what are considered as helpful reviews between Japanese and Western consumers. First, across different cultures, helpful reviews offer reviewer opinions evenly on important dining attributes. In both Japanese and Western consumers' reviews, sentiment expressions are spread more over key review aspects in helpful reviews than they are in all reviews. Second, those spreads are specific to culture. Westerners prefer to see subjective opinions (emotional sentiments) more on service in helpful reviews than all reviews. On the other hand, Japanese customers are more interested in knowing about poor physical environment and bargain price. Westerners are the opposite in this respect; they want to be aware of a great physical environment and excessive price.

This study also demonstrated that aspect-level analysis can reveal more insights into customer preferences in today's globalized business environment. Helpful reviews discuss important issues more equally beyond cultural boundaries. Yet, emphasis on those issues still varies between different cultures.

\section{References}

[1] Baek, H., J. Ahn, and Y. Choi, "Helpfulness of Online Consumer Reviews: Readers' Objectives and Review Cues", International Journal of Electronic Commerce 17(2), 2013, pp. 99-126.

[2] Bagheri, A., M. Saraee, and F. de Jong, "An Unsupervised Aspect Detection Model for Sentiment Analysis of Reviews", In E. Métais, F. Meziane, M. Saraee, V. Sugumaran and S. Vadera, eds., Natural Language Processing and Information Systems. Springer Berlin Heidelberg, 2013, 140-151.

[3] Benedict, R., The chrysanthemum and the sword: Patterns of Japanese culture, Houghton Mifflin Harcourt, 1967.

[4] Blair-Goldensohn, S., K. Hannan, R. McDonald, T. Neylon, G.A. Reis, and J. Reynar, "Building a sentiment summarizer for local service reviews", $W W W$ Workshop on NLP in the Information Explosion Era, (2008), 14-24. [5] Bourgeat, F., C. Borg, N. Bedoin, et al., "Explicit and implicit emotional processing modifications in pharmacoresistant left temporal lobe epilepsy and anxiodepressive disorders", Epilepsy and Behavior 21(4), 2011, pp. 367-372.

[6] Cao, Q., W. Duan, and Q. Gan, "Exploring determinants of voting for the 'helpfulness' of online user reviews: A text mining approach", Decision Support Systems 50(2), 2011, pp. 511-521.

[7] Caudill, W., and G. de Vos, "Achievement, culture and personality: The case of the Japanese Americans", American Anthropologist 58(6), 1956, pp. 1102-1126. [8] Chamberlain, A., D. Ph, and C. Economist, Give to Get : A Mechanism to Reduce Bias in Online Reviews, 2017.

[9] Chik, A., and C. Vasquez, “A comparative multimodal analysis of restaurant reviews from two geographical contexts", Visual Communication 16(1), 2016, pp. 3-26. [10] Choi, S., and A.S. Mattila, "The role of disclosure in 
variable hotel pricing: A cross-cultural comparison of customers' fairness perceptions", Cornell Hotel and Restaurant Administration Quarterly 47(1), 2006, pp. $27-$ 35.

[11] Dhar, R., and K. Wertenbroch, "Consumer Choice Between Hedonic and Utilitarian Goods", Journal of Marketing Research 37(1), 2000, pp. 60-71.

[12] Dyer, J.S., P.C. Fishburn, R.E. Steuer, J. Wallenius, and S. Zionts, "Multiple Criteria Decision Making, Multiattribute Utility Theory: The Next Ten Years", Management Science 38(5), 1992, pp. 645-654.

[13] Folger, R., R.C.-A. in organizational Justice, and U. 2001, "Fairness theory: Justice as accountability", In J. Greenberg and R. Cropanzano, eds., Advances in Organizational Justice. Stanford University Press, 2001. [14] Furrer, O., B.S.-C. Liu, and D. Sudharshan, "The relationships between culture and service quality perceptions: Basis for cross-cultural market segmentation and resource allocation", Journal of service research 2(4), 2000, pp. 355-371.

[15] Gan, Q., B.H. Ferns, Y. Yu, and L. Jin, “A Text Mining and Multidimensional Sentiment Analysis of Online Restaurant Reviews", Journal of Quality Assurance in Hospitality \& Tourism 18(4), 2017, pp. 465-492. [16] Gan, Q., and Y. Yu, "Restaurant rating: Industrial standard and word-of-mouth - A text mining and multidimensional sentiment analysis", Proceedings of the Annual Hawaii International Conference on System Sciences, 2015, pp. 1332-1340.

[17] Ganu, G., N. Elhadad, and A. Marian, "Beyond the stars: Improving rating predictions using review text content", WebDB, (2009), 1-6.

[18] Gao, S., O. Tang, H. Wang, and P. Yin, "Identifying competitors through comparative relation mining of online reviews in the restaurant industry", International Journal of Hospitality Management 71(May 2017), 2018, pp. 19-32. [19] Harris, P., R. Rettie, and C. Cheung, "Adoption and usage of m-commerce: a cross-cultural comparison of Hong Kong and the United Kingdom", Journal of Electronic Commerce Research 6(3), 2005, pp. 210-224. [20] Hofstede, G., M.H. Bond, and C. Luk, "Individual perceptions of organizational cultures: A methodological treatise on levels of analysis", Organization Studies 14(4), 1993, pp. 483-503.

[21] Hofstede, G.H., Culture's Consequences: International Differences in Work-related Values/cG. $H$. Hofstede, sage, 1982.

[22] Holmes, E., "When Shopping Online, Can You Trust the Reviews?", Wall Street Journal, 2016.

https://www.wsj.com/articles/when-shopping-online-canyou-trust-the-reviews-1480438071

[23] Hu, N., J. Zhang, and P.A. Pavlou, "Overcoming the Jshaped distribution of product reviews", Commun. ACM 52(10), 2009, pp. 144-147.

[24] Huang, A.H., K. Chen, D.C. Yen, and T.P. Tran, “A study of factors that contribute to online review helpfulness", Computers in Human Behavior 48, 2015, pp. 17-27.

[25] Jaca, C., E. Viles, L. Paipa-Galeano, J. Santos, and R. Mateo, "Learning 5S principles from Japanese best practitioners: case studies of five manufacturing companies", International Journal of Production Research 52(15), 2014, pp. 4574-4586.

[26] Jang, S. (Shawn), Y. Liu, and Y. Namkung, "Effects of authentic atmospherics in ethnic restaurants:

investigating Chinese restaurants", International Journal of Contemporary Hospitality Management 23(5), 2011, pp. 662-680.

[27] Jang, S., Y. Liu, and Y. Namkung, "Effects of authentic atmospherics in ethnic restaurants: investigating Chinese restaurants", International Journal of

Contemporary Hospitality Management 23(5), 2011, pp. 662-680.

[28] Jang, S.S., A. Ha, and C.A. Silkes, "Perceived attributes of Asian foods: From the perspective of the American customers", International Journal of Hospitality Management 28(1), 2009, pp. 63-70.

[29] JETRO, Japanese Food Overseas : Past and Present, 2013.

[30] Jia, S. (Sixue), "Behind the ratings: Text mining of restaurant customers' online reviews", International Journal of Market Research, 2018, pp. 1-12.

[31] Jing, L., X. Xin, and E. Ngai, "An examination of the joint impacts of review content and reviewer characteristics on review usefulness-the case of Yelp.com", 22nd Americas Conference on Information Systems (AMCIS), (2016), 1-5.

[32] Jo, Y., and A.H. Oh, "Aspect and sentiment unification model for online review analysis", Fourth ACM International Conference on Web Search and Data Mining, 2011, 815-824.

[33] Kanayama, H., T. Nasukawa, and H. Watanabe, "Deeper sentiment analysis using machine translation technology", Proceedings of the 20th International Conference on Computational Linguistics, Association for Computational Linguistics (2004), 494-500.

[34] Kivela, J., R. Inbakaran, and J. Reece, "Consumer research in the restaurant environment, Part 1: A conceptual model of dining satisfaction and return patronage", International Journal of Contemporary Hospitality Management 11(5), 1999, pp. 205-222. [35] Korfiatis, N., E. García-Bariocanal, and S. SánchezAlonso, "Evaluating content quality and helpfulness of online product reviews: The interplay of review helpfulness vs. review content", Electronic Commerce Research and Applications 11(3), 2012, pp. 205-217.

[36] Laroche, M., L.C. Ueltschy, S. Abe, M. Cleveland, and P.P. Yannopoulos, "Service quality perceptions and customer satisfaction: evaluating the role of culture", Journal of International Marketing 12(3), 2004, pp. 58-85. [37] Leong, C.K., and K. Tamaoka, "Cognitive Processing of Chinese characters, words, sentences and Japanese kanji and kana: An introduction", In C.K. Leong and K. Tamaoka, eds., Cognitive Processing of the Chinese and the Japanese Languages. Springer Netherlands, Dordrecht, 1998, 1-10.

[38] Li, M.X., L.Q. Huang, C.H. Tan, and K.K. Wei, "Helpfulness of Online Product Reviews as Seen by Consumers: Source and Content Features", International Journal of Electronic Commerce 17(4), 2013, pp. 101-136. [39] Liu, B., "Opinion Mining and Sentiment Analysis", In Web Data Mining. Springer Berlin Heidelberg, 2011, 459- 
526.

[40] Liu, B.S., O. Furrer, and D. Sudharshan, "Culture and Behavioral Intentions Toward Services", Journal of service research 4(2), 2001, pp. 118-129.

[41] Liu, H., and L. Lin, "Food, Culinary Identity, and Transnational Culture: Chinese Restaurant Business in Southern California", Journal of Asian American Studies 12(2), 2009, pp. 135-162.

[42] Liu, Y., and S.C. (Shawn) Jang, "Perceptions of Chinese restaurants in the U.S.: What affects customer satisfaction and behavioral intentions?", International Journal of Hospitality Management 28(3), 2009, pp. 338348.

[43] Mattila, A.S., and P.G. Patterson, "Service Recovery and Fairness Perceptions in Collectivist and Individualist Contexts”, Journal of Service Research 6(4), 2004, pp. 336-346.

[44] Minkov, M., and G. Hofstede, "Hofstede's fifth dimension: New evidence from the World Values Survey", Journal of cross-cultural psychology 43(1), 2012, pp. 3-14. [45] Mudambi, S.M., and D. Schuff, "What Makes a Helpful Online Review? A Study of Customer Reviews on Amazon.com”, MIS Quarterly 34(1), 2010, pp. 185-200. [46] Nakayama, M., "Biases in Consumer Reviews: Implications for Different Categories of Goods", Conf-IRM 2013, (2013), Paper 62.

[47] Nakayama, M., "Exploratory study on the stability of consumer rationality in judging online reviews", Journal of Electronic Commerce in Organizations 15(1), 2017, pp. 122.

[48] Nakayama, M., H. Kanayama, and T. Nasukawa, "Cross-cultural comparisons of review aspect importance", International Conference on Internet Studies, (2015), 1-7. [49] Namkung, Y., and S. (Shawn) Jang, "Does food quality really matter in restaurants? its impact on customer satisfaction and behavioral intentions", Journal of Hospitality \& Tourism Research 31(3), 2007, pp. 387-409. [50] Nasukawa, T., and T. Nagano, "Text analysis and knowledge mining system”, IBM Systems Journal 40(4), 2001, pp. 967-984.

[51] National Highway Traffic Safety Administration, Workforce Assessment: The Future of NHTSA's Defects Investigations, 2015.

[52] Nelson, P., "Advertising as information”, Journal of political economy 82(4), 1974, pp. 729-754.

[53] Ngo-Ye, T.L., A.P. Sinha, and A. Sen, "Predicting the helpfulness of online reviews using a scripts-enriched text regression model", Expert Systems with Applications 71, 2017, pp. 98-110.

[54] Pan, Y., and J.Q. Zhang, "Born Unequal: A Study of the Helpfulness of User-Generated Product Reviews", Journal of Retailing 87(4), 2011, pp. 598-612.

[55] Pantelidis, I.S., "Electronic Meal Experience: A Content Analysis of Online Restaurant Comments", Cornell Hospitality Quarterly 51(4), 2010, pp. 483-491. [56] Rescher, N., Fairness: Theory and practice of distributive justice, Transactional Publishers, New Brunswick, New Jersey, 2002.

[57] Restaurant Engine, "Find Out What Your Patrons Think - 7 Restaurant Review Sites Owners Can Monitor", 2017, 2017. https://restaurantengine.com/restaurant-review- sites/

[58] Ryu, K., H. Han, and T.H. Kim, “The relationships among overall quick-casual restaurant image, perceived value, customer satisfaction, and behavioral intentions", International Journal of Hospitality Management 27(3), 2008, pp. 459-469.

[59] Saad Andaleeb, S., and C. Conway, "Customer satisfaction in the restaurant industry: an examination of the transaction-specific model", Journal of Services Marketing 20(1), 2006, pp. 3-11.

[60] Sackett, D.L., "Bias in analytic research", Journal of Chronic Diseases 32(1-2), 1979, pp. 51-63.

[61] Schmalz, M., M. Carter, and J.H. Lee, "It' s Not You, It' s Me : Identity, Self - Verification , and Amazon Reviews", DATA BASE for Advances in Information Systems 49(2), 2018, pp. 79-92.

[62] Schuckert, M., X. Liu, and R. Law, "Hospitality and Tourism Online Reviews: Recent Trends and Future Directions", Journal of Travel and Tourism Marketing 32(5), 2015, pp. 608-621.

[63] Tax, S.S., S.W. Brown, and M. Chandrashekaran, "Customer Evaluations of Service Complaint Experiences: Implications for Relationship Marketing", Journal of Marketing 62(2), 1998, pp. 60.

[64] Titov, I., and R.T. McDonald, "Modeling Online Reviews With Multi-grain Topic Models", 17th International Conference on World Wide Web, (2008), 111-120.

[65] Vu, H.Q., G. Li, R. Law, and Y. Zhang, "Exploring Tourist Dining Preferences Based on Restaurant Reviews", Journal of Travel Research(OnlineFirst), 2017, pp. 1-19.

[66] Wang, H., S. Gao, P. Yin, and J.N.K. Liu,

"Competitiveness analysis through comparative relation mining Evidence from restaurants' online reviews", Industrial Management and Data Systems 117(4), 2017, pp. 672-687.

[67] Wilson, C., and D.J. Wallis, "Attentional bias and slowed disengagement from food and threat stimuli in restrained eaters using a modified stroop task", Cognitive Therapy and Research 37(1), 2013, pp. 127-138.

[68] Winsted, K.F., "The service experience in two cultures: A behavioral perspective", Journal of Retailing 73(3), 1997, pp. 337-360.

[69] Winsted, K.F., "Evaluating service encounters: A cross-cultural and cross-industry exploration", Journal of Marketing Theory and Practice 7(2), 1999, pp. 106-123. [70] Winsted, K.F., "Patient satisfaction with medical encounters-a cross-cultural perspective", International Journal of Service Industry Management 11(5), 2000, pp. 399-421.

[71] Zhu, J., H. Wang, B.K. Tsou, and M. Zhu, "Multiaspect opinion polling from textual reviews", Proceedings of the 18th ACM conference on Information and knowledge management, 2009, 1799-1802.

[72] Zhu, W.-D.J., B. Foyle, D. Gagné, et al., IBM Watson Content Analytics: Discovering Actionable Insight from Your Content, IBM Redbooks, 2014.

[73] Zhu, W.-D.J., B. Foyle, D. Gagné, et al., IBM Watson Content Analytics: Discovering Actionable Insight from Your Content, IBM Redbooks, 2014. 